\title{
Manufacturer perceptions of the consequences of task and emotional conflict within domestic channels of distribution
}

\author{
Gregory M. Rose ${ }^{\mathrm{a}, *}$, Aviv Shoham ${ }^{\mathrm{b}, 1}$, Stern Neill ${ }^{\mathrm{a}, 2}$, Ayalla Ruvio ${ }^{\mathrm{c}, 3}$ \\ ${ }^{a}$ Milgard School of Business, University of Washington, Tacoma, 1900 Commerce Street, Box 358420, Tacoma, WA 98402-3100, United States \\ ${ }^{\mathrm{b}}$ Graduate School of Business, University of Haifa, Haifa, 31905, Israel \\ ${ }^{\mathrm{c}}$ Graduate School of Management, University of Haifa, Haifa, 31905 Israel
}

\begin{abstract}
This study examines manufacturer' perceptions of task and emotional conflict in domestic channels of distribution. Both are expected to depend on three antecedents (centralization, esprit de corps, and communication barriers) and to affect performance relative to competitors and manufacturer's satisfaction directly and indirectly through strategy quality. The results support a positive link between task and emotional conflict and the deleterious effect of emotional conflict on satisfaction and performance.
\end{abstract}

Keywords: Channels; Distribution; Conflict; Performance

Prior studies examine conflict between manufacturers and channels of distribution from a variety of perspectives (e.g., Lusch, 1976a,b; Michie and Sibley, 1979; Rosenberg and Stern, 1970; Stern and Gorman, 1969). Many scholars have discussed the negative and dysfunctional aspects of conflict (e.g., Brown and Frazier, 1978; Anderson and Narus, 1984) and recommended methods of managing or reducing it (e.g., Frazier and Rody, 1991; Mohr et al., 1996). Others have conceptualized conflict as multi-dimensional, potentially beneficial, and either functional or dysfunctional, depending on the focus of the debate and the source of the disagreement between the parties (e.g., Rosenberg and Stern, 1970; Hunt, 1995).

Discussions of the potential benefits of positive conflict have a long history in marketing (e.g., Rosenberg and Stern, 1970; Hunt, 1995). These discussions, moreover, have recently been reinvigorated by intraorganizational research demonstrating the positive aspects of issue-oriented task conflict within an organization (Amason, 1996; Jehn, 1994; Menon et al., 1996). Task conflict produces superior decision-making because it elicits a diversity of viewpoints and results in a more thorough consideration of multiple factors. Emotional conflict, on the other hand, is personal, denigrates a relationship, and centers on disagreements between parties. Thus, previous examinations of intraorganizational conflict have found that while emotional conflict reduces performance, task conflict increases performance by increasing the quality of the strategy employed (Menon et al., 1996).

Similar results, however, have not been found across organizations. Task conflict was negatively related to business performance within international channels of distribution (Rose and Shoham, 2004) and lowered network member satisfaction between MBA students representing different retail stores within a mall (Bradford et al., 2004). Thus, previous research across organizations directly contradicts the findings of research within an intraorganizational context.

This study addresses this discrepancy by examining the influence of task and emotional conflict within domestic channels of distribution. One of Rose and Shoham's (2004, p. 947) central arguments was that "international channels of distribution may be particularly prone to negative conflict," because 
"cultural differences may decrease opportunities for meaningful interactions and the successful resolution of task conflict." Thus, the deleterious effects of task conflict may be specific to the cross-national context of international channels of distribution. Alternatively, intraorganizational processes may present a unique environment where frequent communication, informal member contact, affiliation, and common group member identification facilitate constructive task-oriented debate among members. Hence, interorganizational conflict (across organizations) may inhibit performance within channels of distribution. This study seeks to resolve this issue by specifically testing the effects of interorganizational conflict in domestic channels of distribution. It also directly tests Rose and Shoham's (2004) assertion that task-related differences of opinion may result in personal, affective, emotional conflict that lessens performance.

Thus, this paper contributes to the literature in three ways. First, it examines the impact of emotional and task conflict within domestic channels of distribution. Second, it empirically examines the relationship between emotional and task conflict. Third, a partially mediated model is proposed that includes the direct impact of task and emotional conflict on channel performance and satisfaction as well as their mediated impact through quality of strategy.

\section{Theoretical background}

Conflict, both within organizations and between manufacturers and channels, has generally been viewed as inhibiting performance and denigrating the relationship. For example, Stern and El-Ansary (1992) describe conflict as originating from behaviors by one party that impede/inhibit the attainment of another party's goals. Thus, conflict is to be managed to reduce its potentially dysfunctional aftermath (Stern and El-Ansary, 1992).

However, moderate conflict may also be functional within the proper context. Previous intraorganizational research has acknowledged the potentially positive impact of conflict (Anderson and Narus, 1984; Amason, 1996; Hunt, 1995; Reve and Stern, 1979). These authors have differentiated between task and emotional conflict (Amason, 1996), functional and dysfunctional conflict (Hunt, 1995), and affective and substantive conflict (Peled, 1996). Consequently, we utilize a multi-dimensional framework to examine task and emotional conflict. Task conflict centers on disagreements about the means of achieving specific ends (Amason, 1996; Jehn, 1994), while emotional conflict results from interpersonal disagreements and personality incompatibilities.

\subsection{Conflict antecedents}

\subsubsection{Centralization}

Centralization is defined as a concentration of decisionmaking at a high level of an organization (Menon et al., 1996). In an interorganizational context, centralization of decisionmaking at the manufacturer's end of the dyad should result in conflict with the channel because it reduces the latter's flexibility and autonomy (Etgar, 1979; Wall and Callister, 1995). Transaction cost economics provides another theoretic rationale for the negative impact of centralization, which is predicated on the idea that centralization may increase opportunistic behavior, reducing performance (Dwyer and Oh, 1987). Thus:

H1. The higher the level of manufacturer centralization the higher the level of task $\left(\mathrm{H}_{1 \mathrm{a}}\right)$ and emotional $\left(\mathrm{H}_{1 \mathrm{~b}}\right)$ conflict.

\subsubsection{Esprit de corps}

Esprit de corps involves a sense of team spirit. It facilitates trusting relationships, high employee commitment, and pride in being a member of the organization (Menon et al., 1996). Thus, esprit de corps promotes agreement and commitment and reduces conflict in several ways. First, it may be indicative of a participative leadership style within the dyad, which reduces conflict (Schul et al., 1983). Second, esprit de corps is instrumental in creating super-ordinate goals and a total system perspective that reduces conflict (Speh and Bonfield, 1978). Finally, team spirit is useful in creating a fruitful background for the development of mutually acceptable channel member roles (Etgar, 1979). Thus:

H2. The higher the level of esprit de corps, the lower the level of task $\left(\mathrm{H}_{2 \mathrm{a}}\right)$ and emotional $\left(\mathrm{H}_{2 \mathrm{~b}}\right)$ conflict.

\subsubsection{Communication barriers}

Communication barriers refer to factors that reduce or inhibit discussions (Menon et al., 1996). Effective communication leads to trust between partners (Anderson and Narus, 1984), clearer goals, channel consensus, and greater channel coordination (Stern and Gorman, 1969). Mutual communication fosters understanding and reduces perceptions of conflict (Stern and ElAnsary, 1992). Thus:

H3. The lower the level of communication barriers the lower the level of task $\left(\mathrm{H}_{3 \mathrm{a}}\right)$ and emotional $\left(\mathrm{H}_{3 \mathrm{~b}}\right)$ conflict.

\subsection{The relationship between task and emotional conflict}

Previous authors have emphasized the importance of managing conflict (Bradford et al., 2004) and asserted that task conflict can turn personal and spill over into emotional conflict (Jehn, 1994). Previous research has also asserted that task conflict may produce emotional conflict in international channels of distribution (Rose and Shoham, 2004); however, this assertion was never explicitly tested. We explicitly test the potential positive relationship between task and emotional conflict in this study.

H4. The higher the level of task conflict the higher the level of emotional conflict.

\subsection{Conflict consequences}

Our approach is similar (but not identical) to that of Menon, Bharadwaj, and Howell's (1996) and Rose and Shoham's (2004). Consistent with them, we include quality of strategy as a mediator of the conflict-performance relationship. However, our approach differs in that quality of strategy does not completely mediate the relationship, because our model also includes direct relationships 
between the two types of conflict and our performance outcomes. These relationships are discussed below.

\subsubsection{Quality of marketing strategy}

The causes and consequences of the quality of marketing strategy has received a relatively small amount of attention in academic research considering its importance (Menon et al., 1996; Rose and Shoham, 2004). Bonoma and Clark (1988, pp. 37-38) noted that "few authors discuss quality of effort in any form." They argued that high-quality marketing strategy involves the quality of coping with change and crisis, thus moving the organization toward quality and enhancing performance. Thus, we define the construct as the quality of the design and execution of the marketing strategy for the territory covered by the channel (Menon et al., 1996).

The quality of the marketing strategy is a partial mediator of the conflict-performance relationship. Conflict results in distortion and withholding of information between dyad members, mistrust, and obstacles to effective and efficient decision-making (Ruekert and Walker, 1987). Amason (1996) documented the harmful impact of emotional conflict on decision quality in an intraorganizational context (Menon et al., 1996). Similar findings have also been found in the channels literature, where conflict reduced dealer satisfaction (Mohr et al., 1996).

Properly managed conflict may also improve decision-making by promoting the free expression of ideas and opinions (Schwenk, 1989), inducing a problem-solving orientation (Isen and Baron, 1991), and promoting creativity (Eisenhardt and Zbaracki, 1992). Thus, conceptually conflict can have a positive or negative effect on the quality of strategy employed. Empirically, Menon, Bharadwaj, and Howell (1996) find that task and emotional conflicts are negatively correlated within an organization, with the former enhancing and the latter detracting from performance. Jehn (1994), interestingly, had similar findings about the effects of these types of conflict, but found a positive relationship between task and emotional conflict. She argued that while group members may be able to distinguish between emotional and task conflict it does not prevent task conflict from turning into emotional conflict. Thus, increased decision quality may come at the expense of future cooperation because functional conflict can inadvertently spur dysfunctional conflict (Amason, 1996).

Overall, previous examinations of conflict within a single organization have found support for the deleterious effects of emotional conflict and some support for the positive effects of task conflict (Amason, 1996; Jehn, 1994; Menon et al., 1996). Both types of conflict, however, have generally had negative effects in an interorganizational context. Both lowered satisfaction in a simulated retail network (Bradford et al., 2004) and performance through the quality of the strategy employed in international channels of distribution (Rose and Shoham, 2004). This study seeks to reexamine and extend these findings to domestic channels of distribution.

H5. The higher the level of task $\left(\mathrm{H}_{4 \mathrm{a}}\right)$ and emotional $\left(\mathrm{H}_{4 \mathrm{~b}}\right)$ conflict the lower the quality of marketing strategy.

Additionally, there should be direct links between conflict and performance. Specifically, Jehn (1994) reported that conflict reduced intragroup performance and satisfaction. Gaski (1984) concluded that conflict reduced channel member' satisfaction and channel performance (see also Michie and Sibley, 1979; Hunt, 1995; Rosenberg and Stern, 1970). Finally, in a study of channels in the Saudi car market, Ahmed and ElMotawa (1997) reported that conflict adversely affected agents' satisfaction with the manufacturers they represent. Thus:

H6. The lower the level of task $\left(\mathrm{H}_{5 \mathrm{a}}\right)$ and emotional $\left(\mathrm{H}_{5 \mathrm{~b}}\right)$ conflict the higher the satisfaction with the channel.

H7. The lower the level of task $\left(\mathrm{H}_{6 \mathrm{a}}\right)$ and emotional $\left(\mathrm{H}_{6 \mathrm{~b}}\right)$ conflict the higher the performance relative to competitors.

Finally, the purpose of any marketing strategy is to effectively and efficiently allocate and use firm resources to attain objectives (Bonoma and Clark, 1988; Menon et al., 1996). In the channel context, such objectives include satisfaction with the channel and performance relative to competitors in the territory served by the channel. Thus:

H8. The lower the level of the quality of strategy the lower the satisfaction with the channel $\left(\mathrm{H}_{8 \mathrm{a}}\right)$ and the lower the performance relative to competitors $\left(\mathrm{H}_{8 \mathrm{~b}}\right)$.

In sum, the model guiding our research is shown in Fig. 1. It includes three antecedents - centralization, esprit de corps, and communication barriers - for two types of conflict (task and emotional). Quality of strategy is modeled as a partial mediator between these types of conflict and the two outcomes performance relative to competitors in the territory and satisfaction with channel performance.

\section{Research methods}

\subsection{Data collection}

Data for this study were collected from Israeli manufacturers in six industries, chosen for diversity of products and markets (food, machinery, packaging, plastics, chemicals, and camping). We sent out 763 questionnaires, 78 of which were returned due to address inaccuracies. Another 28 firms returned the questionnaires and commented that they were irrelevant because they used direct marketing. Thus, the effective response rate was $15 \%$ (98 of 657). The final sample included 21 firms from the food industry, 8 machinery firms, 14 packaging firms, 20 plastics firms, 17 chemicals firms, and 1 camping firm (17 firms did not provide industry classification).

We compared respondents' sales and number of employees to industry-wide data. Firms in our sample tended to be larger than industry means. For example, the mean sales and number of workers in the chemical industry were New Israeli Shekels (NIS) 53.7 million and 55, respectively; they averaged NIS 115.3 million and 705, respectively, in our sample. Mean sales and number of workers for all Israeli industries were NIS 8.5 million and 20, respectively; they averaged NIS 44.7 million and 300, respectively, in our sample. Thus, our results may include larger-than-average Israeli manufacturers. 


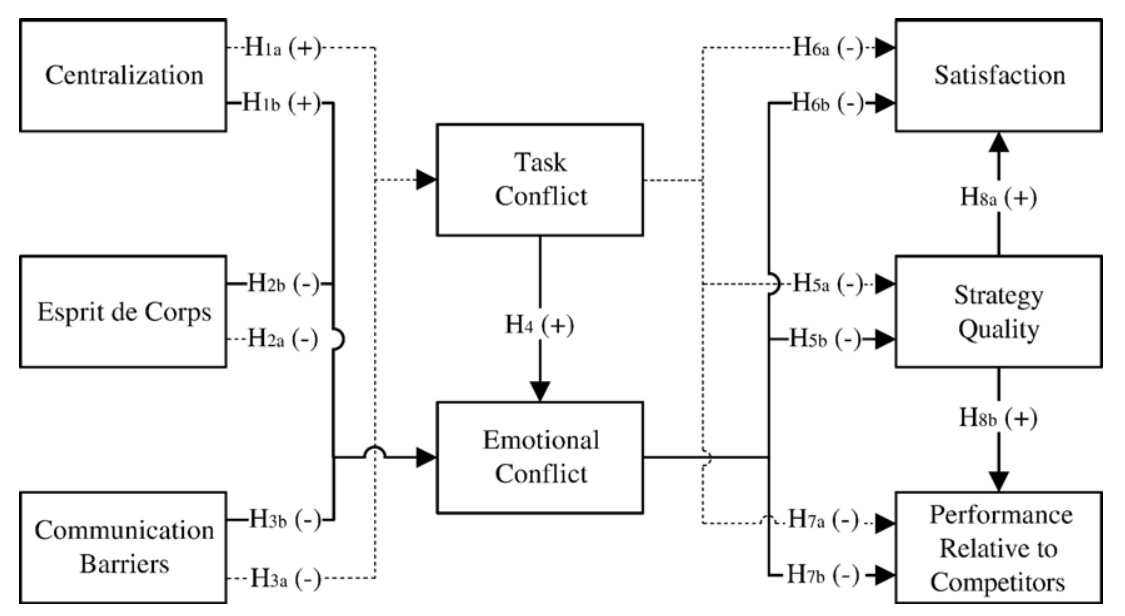

Fig. 1. Channel conflict, its antecedents, and consequences.

\subsection{Operationalization of constructs}

The measures used in this study were based on previous research and were all originally in English. We used two bilingual individuals to translate the items to Hebrew. Then, two different bilingual individuals, blind to the original items, to back-translated the items to English. Another bilingual individual compared equivalency of the original and backtranslated versions. Changes were made by consultation of the five individuals. All of the items used are shown in the Appendix.

Each of the study constructs was operationalized with multiple measures. Only items with item-to-scale correlations $\geq 0.40$ were retained (Churchill, 1991), resulting in the elimination of three items. Table 1 includes means, $\alpha$ reliability coefficients, and correlations for the scales (discussed below).

\subsubsection{Conflict antecedents}

We adapted Jaworski and Kohli's (1993) scale for centralization $(\alpha=0.85)$. The items measure the extent to which decision-making was centralized at the producer's end of the dyad. Esprit de corps $(\alpha=0.87)$, defined as the existence of common goals and objectives, was adapted from Jaworski and Kohli's (1993) team spirit scale. The communication barriers scale was adapted from Jaworski and Kohli's interdepartmental connectedness scale (1993). The reliability for this scale was $\alpha=0.69$.

\subsubsection{Conflict types}

Our study included measures for task and emotional conflict. The items were based on Jehn (1994). The scale for task conflict (four averaged items) showed acceptable internal reliability $(\alpha=0.70)$. The scale for emotional conflict (three averaged items) was also internally reliable $(\alpha=0.77)$.

\subsubsection{Conflict consequences}

We used three outcomes: quality of marketing strategy, satisfaction with the channel, and performance in the territory relative to competitors. Menon, Bharadwaj, and Howell's (1996) operationalization of quality of strategy was modified for this study $(\alpha=0.90)$. The satisfaction items $(\alpha=0.88)$ were based on the seven non-overlapping items used by Gaski (1986) and Dwyer and Oh (1987). Performance in the territory relative to competitors contained four-items $(\alpha=0.83)$.

\section{Results}

\subsection{Model specification, comparisons, and model fit}

All models were testing using AMOS 4. Model 1 examined a fully mediated independent model, where the effects of emotional and task conflict on performance and satisfaction are fully mediated by the quality of strategy and task and emotional conflict are independent. Model 2 examined a similar model except a path was included where task conflict was

Table 1

Scale means, reliability, and inter-scale correlations ${ }^{1}$

\begin{tabular}{|c|c|c|c|c|c|c|c|c|c|c|}
\hline & $\alpha$ & Mean & A & $\mathrm{C}$ & $\mathrm{D}$ & $\mathrm{E}$ & $\mathrm{F}$ & G & $\mathrm{H}$ & I \\
\hline A. Communication barriers & 0.69 & 4.08 & 1.00 & & & & & & & \\
\hline B. Esprit de corps & 0.87 & 3.51 & 0.30 & 1.00 & & & & & & \\
\hline C. Centralization & 0.85 & 2.41 & -0.15 & -0.16 & 1.00 & & & & & \\
\hline D. Emotional conflict & 0.77 & 2.03 & -0.36 & -0.61 & 0.21 & 1.00 & & & & \\
\hline E. Task conflict & 0.70 & 2.21 & -0.22 & -0.40 & 0.10 & 0.53 & 1.00 & & & \\
\hline F. Strategy quality & 0.90 & 3.00 & -0.09 & -0.52 & 0.13 & 0.42 & 0.34 & 1.00 & & \\
\hline G. Performance & 0.83 & 3.19 & -0.36 & -0.33 & 0.23 & 0.23 & 0.30 & 0.43 & 1.00 & \\
\hline H. Satisfaction & 0.88 & 3.94 & 0.22 & 0.56 & -0.01 & -0.54 & -0.53 & -0.58 & -0.29 & 1.00 \\
\hline
\end{tabular}

${ }^{1}$ All $r>0.205$ differ significantly $(p<0.05)$ from zero. 
Table 2

Model fit statistics

\begin{tabular}{lcccccc}
\hline & $\chi^{2}$ & $d f$ & $\chi^{2} / d f$ & IFI & CFI & RMSEA \\
\hline $\begin{array}{l}\text { Model 1* (independent/fully } \\
\text { mediated) }\end{array}$ & 528.3 & 289 & 1.83 & .97 & .97 & .092 \\
$\begin{array}{c}\text { Model } 2 \text { (task } \rightarrow \text { emotional/fully } \\
\text { mediated) }\end{array}$ & 515.6 & 288 & 1.79 & .97 & .97 & .090 \\
$\begin{array}{l}\text { Model } 3 \text { (task } \rightarrow \text { emotional/partially } \\
\text { mediated) }\end{array}$ & 489.7 & 284 & 1.72 & .97 & .97 & .086 \\
\hline
\end{tabular}

*Model 1 is a fully mediated model (the effects of emotional and task conflict on performance and satisfaction are fully mediated by the quality of the strategy), where task and emotional conflict are independent. Model 2 is a fully mediated model where task conflict is posited to lead to emotional conflict. Model 3 is a partially mediated model (the effects of task and emotional conflict have both a direct impact on performance and satisfaction and an indirect influence through the quality of the strategy) with task conflict posited to lead to emotional conflict.

posited to lead to emotional conflict. Model 3 examined a partially mediated model, where the effects of task and emotional conflict have both a direct effect on satisfaction and performance and an indirect effect through quality of strategy.

Model fit statistics for all models are summarized in Table 2. Chi-square difference tests showed that Model 2 improved on Model $1\left(\chi_{1}^{2}=12.7, p<.001\right)$ and Model 3 improved upon Model $2\left(\chi_{1}^{2}=25.9, p<.001\right)$. Thus, the partially mediated model with a path between task and emotional conflict fit the data best.

Model fit statistics for the final model (Model 3) resulted in a $\chi^{2}$ of $489.7(284 d f ; p<0.001)$ and in acceptable fit statistics (Hair et al., 1995). The model's comparative fit index (0.97), root mean square error (0.09), and incremental fit index (0.97) are satisfactory. The final model (as well as the comparative models) included both the measurement and the structural components. Thus, the overall model fit indicated a good fit for both components. The discriminant validity of the two conflict scales and the two outcome scales was also specifically assessed. These analyses showed acceptable discriminant validity. In no case did the estimated confidence interval (within two standard deviations) for the constructs include 1.0. Thus, we proceeded to an examination of the model estimates (Table 3 ). The model explained $26 \%$ and $85 \%$ of the variance in task and emotional conflict, respectively. It explained $35 \%$ of the variance in the quality of strategy, $25 \%$ of the variance in performance relative to competitors, and $63 \%$ of the variance in satisfaction with the channel.

\subsection{Hypotheses tests}

H1 argued that higher levels of centralization of decisionmaking by the manufacturer would lead to higher task $\left(\mathrm{H}_{1 \mathrm{a}}\right)$ and emotional $\left(\mathrm{H}_{1 \mathrm{~b}}\right)$ conflict. The data disconfirmed H1. None of the links between centralization and the two types of conflict reached statistical significance $(p<.05)$. Standardized estimates and $t$-values for these relationships were $-.12(t=-1.15$, $p>.05)$ for task conflict and $-.03(t=-0.38, p>.05)$ for emotional conflict. Unstandardized estimates are presented in Table 3.

Higher levels of esprit de corps were expected to lead to lower levels of task and emotional conflict $\left(\mathrm{H}_{2}\right)$. In support of $\mathrm{H}_{2 \mathrm{a}, \mathrm{b}}$, the relationship between esprit de corps and both task (std. est. $=-.42, t=-3.21, p<.001$ ) and emotional conflict (std. est. $=-.60, t=-4.48, p<.001)$ was negative and significant.

According to $\mathrm{H} 3$, higher communication (as evidenced by lower communication barriers) should result in lower task $\left(\mathrm{H}_{3 \mathrm{a}}\right)$ and emotional $\left(\mathrm{H}_{3 \mathrm{~b}}\right)$ conflict. Task conflict was, as expected negatively associated with communication barriers (std. est. $=$ $-.25, t=-1.86, p<.05)$. The relationship between communication barriers and emotional conflict was directionally in line with expectations (std. est. $=-.07, t=-0.75)$ but failed to reach statistical significance $(p>.05)$. Thus, the data partially supported $\mathrm{H}_{3}$.

Task conflict was expected to be positively associated with emotional conflict (H4). This relationship was empirically supported (std. est. $=-.47, t=3.20, p<.001$ ).

High task and emotional conflict were expected to be related to low quality of strategy (H5). Interestingly, the estimate for the impact of task conflict $\left(\mathrm{H}_{5 \mathrm{a}}\right.$, std. est. $\left.=-.20, t=-.99\right)$ was directionally opposite the hypothesized direction but statistically insignificant $(p<.05)$, while the estimate for emotional conflict was significant and positive as hypothesized (std. est. $=.73$, $t=3.37, p>.001)$. Thus, the data provide partial support to H5 and emphasize the detrimental direct impact of emotional (but not task) conflict on quality of strategy. Recall, however, that

Table 3

Unstandardized estimates and $t$-values for final model ${ }^{1,2,3}$

\begin{tabular}{|c|c|c|c|c|c|}
\hline & $\begin{array}{l}\text { Task conflict } \\
(0.30)^{3}\end{array}$ & $\begin{array}{l}\text { Emotional conflict } \\
(0.89)\end{array}$ & $\begin{array}{l}\text { Low strategy quality } \\
(0.40)\end{array}$ & $\begin{array}{l}\text { Low performance relative to competitors } \\
(0.25)\end{array}$ & $\begin{array}{l}\text { Satisfaction } \\
(0.63)\end{array}$ \\
\hline $\begin{array}{l}\text { Communication } \\
\text { barriers }\end{array}$ & $-0.35(-1.86)^{1,2}$ & $-0.15(-0.75)$ & & & \\
\hline Esprit de corps & $-0.31(-3.21)$ & $-0.62(-4.48)$ & & & \\
\hline Centralization & $-0.11(-1.15)$ & $0.04(0.38)$ & & & \\
\hline Task conflict & & $0.67(3.20)$ & $-0.41(-0.99)$ & $0.33(0.85)$ & $-0.23(-1.34)$ \\
\hline $\begin{array}{l}\text { Emotional } \\
\text { conflict }\end{array}$ & & & $1.05(3.37)$ & $-0.03(-0.09)$ & $-0.25(-1.81)$ \\
\hline $\begin{array}{l}\text { Low strategy } \\
\text { quality }\end{array}$ & & & & $0.42(2.97)$ & $-0.18(-3.03)$ \\
\hline
\end{tabular}

${ }^{1} t$-values are in parentheses.

${ }^{2}$ All $t$-values $\geq|1.645|$ are significant at $p<0.05$.

${ }^{3}$ Squared multiple correlations for structural equations. 
task conflict was directly and positively related to emotional conflict, $\mathrm{H}_{4}$.

We expected low levels of task and emotional conflict $\left(\mathrm{H}_{6}\right)$ to lead to higher satisfaction with the channel and to higher performance relative to competitors $\left(\mathrm{H}_{7}\right)$. The data provide partial support to $\mathrm{H}_{7}$. Although the relationship between task conflict and satisfaction was not statistically significant $\left(\mathrm{H}_{6 \mathrm{a}}\right.$, std. est. $=-.22, t=-1.34, p>.05)$, the relationship between emotional conflict and satisfaction was negative and significant as expected $\left(\mathrm{H}_{6 \mathrm{~b}}\right.$, std. est. $\left.=-.35, t=-1.81, p<.05\right)$. Thus, Hypothesis 6 was partially supported. Hypothesis 7, which posited that task $\left(\mathrm{H}_{7 \mathrm{a}}\right)$ and emotional $\left(\mathrm{H}_{7 \mathrm{~b}}\right)$ conflict would be directly related to low performance relative to competitors, was not supported (std. est. $=.17$ and -.02 , respectively for task and emotional performance, $t=0.85,-0.09, p>.05$ ).

Finally, under H8, it was posited that lower quality of strategies would lead to lower satisfaction with the channel and to lower performance relative to competitors. In support of $\mathrm{H}_{8}$, low quality strategies were significantly and positively associated with low performance (std. est. $=.43, t=2.97, p<.001$ ) relative to competitors and inversely related to high satisfaction with the channel (std. est. $=-.36, t=-3.03, p<.001$ ).

In sum, esprit de corps reduces both emotional and task conflict, communication barriers reduce task conflict, and task conflict is positively associated with emotional conflict. Emotional conflict reduces satisfaction with the channel directly and lowers the quality of strategy employed, which is associated with lower performance relative to competitors and reduced satisfaction with the channel. Thus, while emotional conflict directly impacts satisfaction and lowers the quality of the strategy, which lowers performance and satisfaction; task conflict works indirectly on these variables by increasing emotional conflict.

\section{Discussion}

Organizational behavior scholars have long maintained that functional conflict can spill over into dysfunctional conflict (Deutsch, 1969; Schweiger et al., 1986; Jehn, 1994). However, these assertions have not been tested within the context of a nomological network. This study directly examined manufacturer perceptions of the relationship between task and emotional conflict within domestic channels of distribution. A model is proposed and tested where task conflict leads to emotional conflict, which impacts performance relative to competitors and manufacturer satisfaction with the channel both directly and indirectly through quality of strategy.

Task conflict was not directly related to any of the outcomes examined in this study. The strong relationship between task and emotional conflict, however, suggests that it negatively impacts both performance and satisfaction indirectly by increasing emotional conflict. Thus, we empirically demonstrate the spillover effect of task conflict on emotional conflict and performance.

Several previous studies have reported a positive relationship between functional/task-oriented and emotional/affective conflict (e.g., Amason, 1996; Jehn, 1994; Rose and Shoham, 2004).
Intraorganizational research, however, has generally argued that task-oriented debate enhances performance (e.g., Amason, 1996; Jehn, 1994). Jehn (1994) argued that functional conflict had a positive impact on performance even though she found a positive relationship between task-related and emotional conflict. Amason (1996) argued that the increased decision quality realized from functional conflict generally comes at the expense of group consensus and team member affect (Amason, 1996).

Menon, Bharadwaj, and Howell (1996), in contrast, found a negative relationship between functional and dysfunctional conflict. They examined an intraorganizational context and argued that while dysfunctional conflict decreased decision quality, functional conflict increased the quality of the strategy employed, which increased performance. Thus, previous research within an organization has found both a positive and negative relationship between functional/cognitive/task-oriented and emotional/dysfunctional conflict, but has generally argued that functional conflict is beneficial (regardless of the form of the relationship between the two types of conflict).

We find that task conflict does not improve performance or the quality of strategy employed and leads to emotional conflict within domestic channels of distribution. Thus, the improved performance from issue-oriented task conflict found within an intraorganizational context does not appear to hold within channels of distribution. Rose and Shoham (2004) explored the interorganizational context of international channels of distribution. They found that task and emotional conflict were negatively related to satisfaction and performance through decision quality. We support and expand upon these findings within domestic channels of distribution by testing a partially mediated model that directly examines the relationship between task and emotional conflict. Task conflict increases emotional conflict, which directly reduces satisfaction with the channel and lowers performance relative to competitors and satisfaction (indirectly) by lowering the quality of the strategy. Thus, domestic channels of distribution further demonstrate the deleterious impact of both task and emotional conflict within an interorganizational context.

Domestic channels of distribution present a less extreme context than international channels. International channels present additional cultural and geographic challenges, which exacerbate potential problems in building and maintaining effective understanding and communication between partners. Although domestic channels of distribution still have the associated difficulties of maintaining effective coordination across organizations, domestic channel members are arguably less apt to interpret all types of conflict as negative and allow task conflict to impinge on performance. Thus, our finding that task-oriented conflict is associated with emotional conflict within domestic channels further emphasizes the difficulty of maintaining effective relationships across organizations. Our findings are consistent with previous research within simulated retail networks, where conflict reduced satisfaction (Bradford et al., 2004) and with previous findings regarding member satisfaction within organizational behavior (e.g., Amason, 1996). The reduced opportunities for frequent and informal contact, camaraderie, and team building across partners rather than within a single organization appears to ameliorate the 
positive impact of task performance within channels of distribution and accentuate the tendency of task conflict to become personal and turn into emotional conflict.

The antecedents and consequences for these two types of conflict were also examined. Centralization did not affect either type of conflict. Menon, Bharadwaj, and Howell (1996), in contrast, found that centralization affected conflict among American managers. Centralization may be more difficult to impose among Israeli managers and/or across organizations rather than within an organization (as was the case in the US study). Hence, it would be instructive to examine the impact of centralization in other countries and across other interorganizational contexts.

Communication barriers increased emotional conflict in our study, which is consistent with previous intraorganizational research (Barclay, 1991; Menon et al., 1996). Thus, our findings extend previous findings for communication barriers to an interorganizational setting.

Esprit de corps lessened both emotional and task conflict. This finding is consistent with Amason (1996), who argued that task conflict increases the quality of the decision but often inhibits a group from interacting effectively in the future. Additional research, preferably longitudinal research, should explore the long-term reciprocal impact of esprit de corps and task and emotional conflict.

Overall, our results empirically demonstrate the negative consequences of emotional conflict and the potential of task conflict to promote this type of conflict within domestic channels of distribution. Previous findings and assertions regarding the positive impact of functional, task conflict do not appear to be applicable to channels of distribution. Future research should further assess the mechanisms by which functional, task conflict can become personal both within and across organizations.

\section{Limitations and managerial implications}

\subsection{Limitations}

Before discussing the implications of our findings, we recognize several limitations. First, our data were generated from larger-than-average Israeli firms. Second, our sample is based on firms from six industries, which were combined into a single database. To assess the potential impact of this limitation, we conducted nine one-way ANOVA models with industry as the distinguishing factor. Only one of these ANOVA models (for centralization) resulted in a significant industry effect. Thus, it appears that the firms from the five industries have mostly similar means on eight of the nine study constructs.

Third, our data was collected in Israel, raising a question about the generalizability of the findings to firms in other countries. As is the case for any study in one nation, culture may affect some of the findings reported.

\subsection{Managerial implications}

Scholars have long held that conflict resolution is an important element in managing relationships between firms
(Lusch, 1976a,b; Michie and Sibley, 1979; Rosenberg and Stern, 1970; Stern and Gorman, 1969). We find that both task and emotional conflicts can lower performance and/or satisfaction within the manufacturer-channel dyad (either directly and/ or indirectly) and should attract managerial attention. In this respect, communication barriers should be lowered and esprit de corps encouraged. Of the two types of conflict, we successfully explained more of the variance in emotional $\left(r^{2}=0.85\right)$ than in task conflict $\left(r^{2}=0.26\right)$. Importantly, the former has a stronger impact on performance.

Esprit de corps had the strongest impact on conflict. Thus, promoting team spirit should be the prime mechanism used. Creating dyadic team spirit may require the manufacturer to increase the availability of contact personnel to the channel. The focal firm may choose to compensate such personnel for actions that result in enhanced team spirit. To be effective, such an emphasis needs to be measured periodically. Moreover, manufacturers should provide opportunities for formal and informal exchanges of information between contact personnel at all levels of both organizations (senior and junior). Frequent communication along with esprit de corps should lower both actual and perceived conflict.

The findings demonstrate that quality of strategy mediates the conflict-performance relationship. Managers should extend efforts to promote both the quantity of strategic planning and its quality. Bonoma and Clark (1988) argued that the quality of marketing effort is rarely discussed or modeled. Our research corroborates the important role of marketing strategy formulation and implementation on both channel satisfaction and performance. Thus, our research has examined the impact of task and emotional conflict and the quality of strategy employed on domestic channels of distribution. Future research should assess the impact of these types of conflict within other interorganizational settings.

\section{Appendix A. Items and scales}

A. Communication barriers (5-point scales; $1=$ definitely disagree to $5=$ definitely agree; $\alpha=0.69$ ).

1. In the relationships between the firm and its channel, it is easy to talk with virtually anyone you need to regardless of rank or position.

2. There is ample opportunity for informal "hall talk" among individuals from the firm and its channel.

3. People from our firm and from the channel feel comfortable to call each other when the need arises.

4. Managers in our firm discourage employees from talking with their channel counterparts unless it is absolutely workrelated (reversed).

5. People from the channel are quite accessible to those in our firm.

6. Junior managers in our firm can easily schedule meetings with their channel counterparts.

C. Esprit de corps (5-point scales; $1=$ definitely disagree to $5=$ definitely agree; $\alpha=0.87)$. 
1. People at the manufacturer's firm are genuinely concerned about the needs and problems of their channel counterparts.

2. A team spirit pervades all of our and the channel's ranks.

3. Working within this firm's and its channel is like being a part of a big family.

4. People in the firm and its channel feel emotionally attached to each other.

5. People in the firm and its channel feel like they are "in it together".

6. The relationship between the firm and its channel lacks an "esprit de corps" (reversed).

7. People in the firm and its channel view themselves as independent individuals who have to tolerate the others (reversed).

D. Centralization (5-point scales; $1=$ definitely disagree to $5=$ definitely agree; $\alpha=0.85$ ).

1. There can be little action taken by the channel until we approve a decision.

2. A channel that wants to make its own decisions will be quickly discouraged here.

3. Even small matters have to be referred by the channel to someone at the firm for a final answer.

4. The channel has to ask us before they do almost anything.

5. Any decision the channel makes has to have our approval.

E. Emotional Conflict (5-point scales; $1=$ not at all to $5=$ very much; $\alpha=0.77$ ).

1. To what extent was friction present in your relationship with the channel (deleted after purification).

2. How much anger is present in your relationship with your channel.

3. To what extent are there personality clashes in your relationship with your channel.

4. To what extent are there emotional tensions in your relationship with your channel.

F. Task Conflict $(5$-point scales; $1=$ not at all to $5=$ very much; $\alpha=0.70$ ).

1. To what extent are there differences of opinions between you and the channel regarding the tasks the channel does for you.

2. How often do people in your firm disagree with people from the channel about the work they do for you.

3 . How often do you disagree with your channel about the tasks they perform for you.

4. How often do you and the channel disagree about ideas regarding the channel's tasks.

G. Strategy Quality (7-point scales; $1=$ very high to $7=$ very low; $\alpha=0.90$ ). "Different firms develop different strategies to manage their relationships with their channels of distribution (distributors, agents, etc.). For the channel you referred to in answering this questionnaire, how would you rate the quality of your marketing strategy?
1. The quality of strategy formulation.

2. The quality of strategy application.

3. The innovativeness of the marketing strategy.

4. The comprehensiveness of the marketing strategy.

5. The quality of strategy execution.

H. Performance Relative to Competitors (7-point scales; $1=$ much larger than competitors to $7=$ much smaller than competitors; $\alpha=0.83$ ). How would you rate your outcomes in the territory served by the channel relative to your competitors in the same territory on:

1. market share

2. increase in market share

3. profitability on sales

4. increase in profitability on sales

I. Satisfaction. (5-point scale; $1=$ definitely disagree to $5=$ definitely agree; $\alpha=0.88)$.

1. In general, I am pretty satisfied with my relationship with the agent/distributor.

2. Overall, the agent/distributor is a good company to do business with.

3. All in all, the agent/distributor has been very fair with us.

4. Overall, the agent's/distributor's policies and programs benefit my firm.

5. We would discontinue selling through this agent/distributor if we could (reversed).

6. If we had to do it all over again, we would not do business with this agent/distributor (reversed).

7. We are satisfied with the services we get from this agent/ distributor.

\section{References}

Ahmed Ahmed A, El-Motawa Ahmed A. Communication and related channel phenomena in international markets: the Saudi car-market. J Glob Mark 1997;10(3):67-82.

Amason Allen C. Distinguishing the effects of functional and dysfunctional conflict on strategic decision making: resolving a paradox for top management teams. Acad Manage J 1996;39(1):123-48.

Anderson James C, Narus James A. A model of distributor's perspective or distributor-manufacturer working partnership. J Mark 1984;48(4):62-74.

Barclay Donald. Interdepartmental conflict in organizational buying: the impact of organizational context. J Mark Res 1991;26(2):145-59.

Bonoma Thomas V, Clark Bruce H. Marketing performance assessment. Boston: Harvard Business School Press; 1988.

Bradford Kevin D, Stringfellow Anne, Weitz Barton. Managing conflict to improve the effectiveness of retail networks. J Retail 2004;80:181-95.

Brown James R, Frazier Gary L. The application of channel power: its effects and connotations. In: Jain Subhash C, editor. Research Frontiers in Marketing: Dialogues and Directions. Chicago: American Marketing Association; 1978. p. 266-70.

Churchill Gilbert A. Basic Marketing Research. Fort Worth, TX: The Dryden Press; 1991

Deutsch M. Conflicts: productive and destructive. J Soc Issues 1969;25:7-41.

Dwyer Robert F, Oh Sejo. Output sector munificence effects on the internal political economy of marketing channels. J Mark Res 1987;24(4):347-58.

Eisenhardt Kathleen M, Zbaracki Mark J. Strategic decision making. Strateg Manage J 1992;13:17-37. 
Etgar Michael. Sources and Types of Intrachannel Conflict. J Retail 1979;55(1):61-78

Frazier Gary L, Rody Raymond C. The use of influence strategies in interfirm relationships in industrial product channels. J Mark 1991;55(1):52-69.

Gaski John F. The theory of power and conflict in channels of distribution. J Mark 1984;48(3):9-29.

Gaski John F. Interrelations among a channel entity's power sources: impact of the exercise of reward and coercion on expert, referent, and legitimate power sources. J Mark Res 1986;23(1):62-77.

Hair Jr Joseph F, Anderson Rolph E, Tatham Ronald L, Clark William C. Multivariate data analysis. Englewood Cliffs, NJ: Prentice Hall; 1995.

Hunt Kenneth A. The relationship between channel conflict and information processing. J Retail 1995;71(4):417-26.

Isen Alice M, Baron Robert A. Positive affect as a factor in organizational behavior. Res Organ Behav 1991;13:1-53.

Jaworski Bernard J, Kohli Ajay K. Market orientation: antecedents and consequences. J Mark 1993;57(3):53-70.

Jehn Karen A. Enhancing effectiveness: an investigation of advantages and disadvantages of value-based intragroup conflict. Int J Confl Manage 1994;5(3):223-38.

Lusch Robert F. Channel conflict: its impact on retailer operating performance. J Retail 1976a;52:3-12 [Summer].

Lusch Robert F. Sources of power: their impact on intrachannel conflict. J Mark Res 1976b;13(4):382-90.

Menon Anil, Bharadwaj Sundar G, Howell Roy. The quality and effectiveness of marketing strategy: effects of functional and dysfunctional conflict in intraorganizational relationships. J Acad Mark Sci 1996;24(4):299-313.

Michie Donald A, Sibley Stanley D. Channel conflict, competition, and cooperation: theory and management. In: Lusch Robert F, Zinszer Paul H, editors. Contemporary Issues in Marketing Channels. Norman, OK: University Printing Services, the University of Oklahoma; 1979.
Mohr Jakki J, Fisher Robert J, Nevin John R. Collaborative communication in interfirm relationships: moderating effects of integration and control. J Mark 1996;60(3):103-15.

Peled Lisa Hope. Demographic diversity, conflict, and work group outcomes: an intervening process theory. Organ Sci 1996;7(6):615-31.

Reve T, Stern Louis W. Interorganizational relations in marketing channels. Acad Manage Rev 1979;4:405-16 [Fall].

Rose Gregory M, Shoham Aviv. Interorganizational task and emotional conflict with international channels of distribution. J Bus Res 2004;57:942-50.

Rosenberg Larry J, Stern Louis W. Toward the analysis of conflict in distribution channels: a descriptive model. J Mark 1970;34(4):40-6.

Ruekert Robert W, Walker Jr Orville C. Interactions between marketing and R and D departments in implementing different business strategies. Strateg Manage J 1987;8:233-48 [May-June].

Schul Patrick L, Pride William M, Little Taylor L. The impact of channel leadership behavior on intrachannel conflict. J Mark 1983;47(3):21-34.

Schweiger DM, Sanberg WR, Ragan JW. Group approaches for improving strategic decision making: a competitive analysis of dialectical inquiry, devil's advocacy, and consensus approaches to strategic decision making. Acad Manage J 1986;29:51-71.

Schwenk Charles R. A meta-analysis on the comparative effectiveness of devil's advocacy and dialectical inquiry. Strateg Manage J 1989;10:303-6.

Speh Thomas W, Bonfield EH. The control process in marketing channels: an exploratory investigation. J Retail 1978;54:14-6 [Spring].

Stern Louis W, El-Ansary Adel I. Marketing channels. Englewood Cliffs, NJ: Prentice-Hall; 1992.

Stern Louis W, Gorman Ronald H. Conflict in distribution channels: an exploration. In: Stern Louis W, editor. Distribution Channels: Behavioral Dimensions. NY: Houghton Mifflin; 1969. p. 156-75.

Wall James A, Callister Ronda Roberts. Conflict and Its Management. J Manage 1995;21(3):515-58. 